\title{
Adaptation to ex vitro conditions of Stevia rebaudiana (Bertoni) Hemsl. regenerants
}

\author{
L.P. Khlebova ${ }^{1}$, A. Orazov ${ }^{2}$, A.M. Titova ${ }^{1}$, A.V. Pirogova ${ }^{1}$ \\ ${ }^{1}$ Altai State University, 61 Lenina prospect, Barnaul, 656049, Russia. \\ ${ }^{2}$ Al-Farabi Kazakh National University, Almaty, Kazakhstan \\ E-mail: hlebova61@mail.ru
}

Received: 14.08.2019. Accepted: 26.09.2019

\begin{abstract}
Stevia rebaudiana (Bertoni) Hemsl. belongs to Asteraceae family and is of great importance for pharmaceutical and food industries. Stevioside obtained from the leaves of this plant is regarded as a valuable natural sweetener. Low seed fertility is one of the most important problems in stevia production. It multiplies almost exclusively in a vegetative way. Plant tissue culture is an efficient method for mass propagation of $S$. rebaudiana. We studied the effect of various concentrations of auxins on rooting stevia shoot cuttings under in vitro conditions. We found that adding $0.6-1.0 \mathrm{mg} \mathrm{l}^{-1}$ IBA or $0.2 \mathrm{mg} \mathrm{l}^{-1}$ IAA to the $B_{5}$ medium is effective for rooting the shoot fragments of this species. The regenerants were adapted to ex vitro conditions for 3 weeks on a hydroponic setup filled with a solution of mineral salts according to the quarter-strength Murashige and Skoog (MS) basal medium modified by the content of $\mathrm{KH}_{2} \mathrm{PO}_{4}$ and $\mathrm{NH}_{4} \mathrm{NO}_{3}$. Using a triple concentration of $\mathrm{KH}_{2} \mathrm{PO}_{4}\left(510 \mathrm{mg} \mathrm{l}^{-1}\right)$ during the first week of adaptation and a full concentration of $\mathrm{NH}_{4} \mathrm{NO}_{3}$ (1650 mg l-1) over the next 2 weeks ensures $100 \%$ acclimatization of stevia regenerants to ex vitro conditions. The replacement of agar in the nutrient medium with a perlite-vermiculite mixture in the ratio of $1: 3$ stimulated the transition of regenerants to the photomyxotrophic type of nutrition. The use of a porous substrate provided a decrease in humidity inside the culture vessels, which led to forming both leaves with well-functioning stomata and a branched root system with root hairs. The stevia regenerants propagated in vitro on a porous substrate did not require special conditions for the ex vitro acclimatization. The yield of surviving plants in the greenhouse was $100 \%$.
\end{abstract}

Key words: Stevia rebaudiana Bertoni; Natural sweetener; In vitro propagation; Auxin; Rooting; Acclimatization; Porous substrate; Photomyxotrophic micropropagation

\section{Introduction}

The introduction of medicinal plants, sweeteners, among which the most practically valuable is Stevia rebaudiana (Bertoni) Hemsl. (Asteraceae), is of great importance for pharmaceutical and food industries. Stevia is a South American species, which is indigenous to Paraguay. Among 154 representatives of the genus Stevia, S. rebaudiana is one of two species which produce sweet steviol glycosides. Stevia extract have been used as a natural sweetener and customary medicine by the indigenous inhabitants of South America for several hundred years. S. rebaudiana began to be cultivated in the countries of Latin America and Southeast Asia in the late 50 s of the last century. Extensive attempts have been undertaken to introduce it, as a crop, in a number of countries, including the United States, Canada, Russia, Ukraine, Korea, Japan, India. Stevia is currently grown mainly in China, and the main market is in Japan (Verzilina, 2005; Kustova, 2013; Gantait et al., 2014). The introduction of $S$. rebaudiana in a temperate climate of Russia showed a high ability of plants to adapt to the soil and climatic conditions in the Central Black Earth Region, Stavropol Territory, Primorsky Territory (Sikorskaya, 2004; Kononova et al., 2012; Galdina, 2015).

The species is diploid and has 22 chromosomes, which are characteristics for most of the American member of the genus Stevia (Frederico et al., 1996). The plant is a herbaceous perennial shrub with annually dying and newly growing brittle squarish stem reaching $80 \mathrm{~cm}$ in length. The leaves are located opposite, sessile. The inflorescence is a centripetal head. The ray florets are small arranged in an irregular fashion, with white long petals (Skaria et al., 2004). This rare plant contains a whole complex of sweet substances, diterpene glycosides, which are contained in all organs of the plant. Stevioside, rebaudioside $A$, rebaudioside $C$ and dulcoside $A$ are the main components of stevia (Chatsudthipong and Muanprasat, 2009). The amount of steviol glycosides has been found to decline in the following order: leaves, flower, stems, seeds, roots. The greatest interest in practical terms is stevioside, whose content in leaves reaches $6-10 \%$ of total dry weight. The maximal content of stevioside in leaves is achieved during the formation of flower buds and then it gradually declines. The compound is 50-400 times sweeter than sucrose, very low in calories and is used in the prevention of diabetes and obesity (Madan et al., 2010). It has been established that the presence of steviosides normalizes metabolism, restores the antitoxic function of the liver, improves the process of lipid peroxidation and does not increase the blood sugar content (Gantait et al., 2014).

The peculiarity of stevia is that it multiplies almost exclusively in a vegetative way. Seed germination is very poor because of infertility (Kumar, 2013). In addition, plant grown from seed does not allow the production of homogenous plant population resulting in great variability in chemical composition (Brandle and Telmer, 2007; Kovylyaeva et al., 2007). It is usually propagated by cuttings, sprouts in the lower parts of the stem or by dividing the bush (Smitha and Umesha, 2011). Depending on the density of planting, it is necessary to plant from 50,000 to 100,000 plants on 1 hectare. Obtaining this quantity of planting material using conventional breeding methods takes quite a long time. Therefore, tissue culture is a way to create a large number of high-quality stevia planting material (Ahmed et al., 2007; Pande and Gupta, 2013; Islam and Tareq, 2015; Bhingradiya et al., 2016; Ghaheri et al., 2017; Ghorbani et al., 2017; Singh et al., 2017). It is known that the stage of adaptation of regenerants to ex vitro conditions is one of the responsible and time-consuming in the process of in vitro plant propagation. The death of regenerants significantly 
reduces the efficiency of micropropagation. The present study was aimed at the developing an efficient protocol for successful in vitro rooting of stevia shoot fragments and subsequent acclimatization of regenerants to ex vitro conditions.

\section{Materials and Methods}

Materials for the study were sterile stevia plants grown in vitro. To obtain them, small segments (about $1.5 \mathrm{~cm}$ in length) of stevia shoots were introduced into in vitro culture after washing in running tap water for 30 minutes and sterilizing in a $2 \%$ solution of lysoformin for 15 minutes. Then, the explants were washed 4 times with sterile water and placed on $B_{5}$ medium containing $4.5 \%$ sucrose, $0.8 \%$ agar and $0.6 \mathrm{mg} \mathrm{l}^{-1} \mathrm{IBA}$. The $\mathrm{pH}$ of the nutrient medium was adjusted to $5.7-5.8$ prior to autoclaving at $121^{\circ} \mathrm{C}$ for 20 min. The cultures were incubated at a temperature of $25 \pm 2{ }^{\circ} \mathrm{C}$ with $55-60 \%$ relative humidity, under conditions of a photoperiod (16/8 hours light/dark cycles) provided by cool white fluorescent tubes with 3000 lux intensity. After 18-20 days of cultivation, sterile shoots developed. For further clonal micropropagation, plant stems were divided into fragments with two oppositely located axillary buds and placed on $B_{5}$ medium containing various concentrations of IBA $\left(0.05-3 \mathrm{mg} \mathrm{l}^{-1}\right)$ and IAA $\left(0.05-3\right.$ mg l$\left.{ }^{-1}\right)$. The duration of the passage was 21 days. The growth and development of regenerants were evaluated by the frequency of rhizogenesis (\%), the number of roots (pcs./explant), the total length of the roots $(\mathrm{cm})$, the height of the shoot (cm). In addition, the presence or absence of callus on the basal part of the shoot was marked. After 21 days of cultivation, rooted plants were removed from the flasks, carefully washed with sterile water to remove the agar medium. The regenerants were adapted to ex vitro conditions for 3 weeks on a hydroponic setup filled with a solution of mineral salts according to the quarter-strength Murashige and Skoog (MS) basal medium modified by the content of $\mathrm{KH}_{2} \mathrm{PO}_{4}$ and $\mathrm{NH}_{4} \mathrm{NO}_{3}$. The experiment was performed in 5 replicates. Five explants per each replicate were used. Mean values were compared according to least significant differences test (LSD) at $P<0.05$.

The photomixotrophic technique included cultivating segments of stevia stems in $250 \mathrm{ml}$ flasks on a $1: 3$ mixture of perlite and vermiculite with the addition of a solution of mineral salts according to the basal medium $\mathrm{B}_{5}$. The perlite-vermiculite mixture ( $2 \mathrm{~g}$ ), a solution of mineral salts $(25 \mathrm{ml}), 0.2 \mathrm{mg} \mathrm{l}^{-1}$ IAA were placed in a flask and autoclaved at $121^{\circ} \mathrm{C}$ for 30 minutes. Regenerants were cultured on the substrate for 3 weeks. Cultivation conditions were as described above. Rooted stevia shoots were planted in a greenhouse in pots in a substrate consisting of peat moss, vermicompost and sand in equal proportions. Peat moss has a high acidity, therefore, to normalize the acid-alkaline balance, dolomite flour is added to the substrate. The experiment was performed in 3 replicates. Acclimatization success was estimated by the number of surviving plants (\%).

\section{Results}

The plants of $S$. rebaudiana raised from elite germplasm through tissue culture are genetically pure plants, free from all pathogens. They have excellent vigor and can be planted throughout the year (Jain et al., 2014). Plant regeneration of stevia from in vitro culture can be achieved by either organogenesis or embryogenesis. At present, direct regeneration of plantlets via adventitious shoot bud induction from nodal explants is considered to be the preferred method (Singh et al., 2017). Some researchers use MS medium without growth regulators during the reproduction of stevia in vitro. However, not all shoot fragments are able to regenerate roots or their number is insufficient for subsequent growth under ex vitro conditions. In addition, root hairs often do not develop on the roots. It also complicates the acclimatization of regenerants in the soil under non-sterile conditions. Therefore, we investigated the effect of various growth regulators on the induction of root regeneration in shoot cuttings and the subsequent growth and development of regenerants. In the nutrient medium $B_{5}$, various concentrations of IBA and IAA were introduced as the most frequently used rhizogenesis inducers. The results of the experiment are presented in Figure 1.

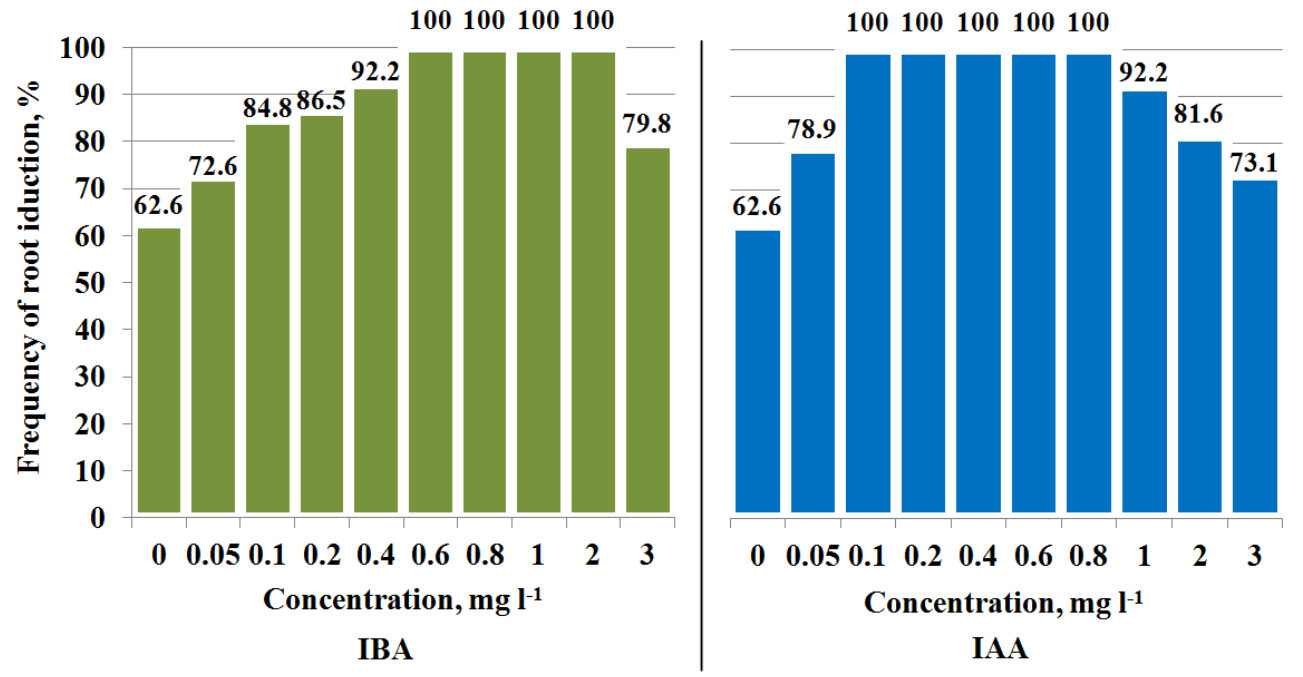

Figure 1. Effect of auxins on in vitro root induction in Stevia rebaudiana (Bertoni) Hemsl. after cultivation for 21 days.

The total length of the roots regenerated in one shoot varied depending on the IBA concentration. It increased in comparison with the control, reaching a maximum value with the addition of $1 \mathrm{mg} \mathrm{l}^{-1}$. Then the parameter was significantly decreased when using 2$3 \mathrm{mg} \mathrm{l}^{-1}$ of the auxin. The length of shoots was maximum at a growth regulator concentration of $1 \mathrm{mg} \mathrm{l}^{-1}($ Table 1$)$.

Table 1. The influence of auxins on the development of Stevia rebaudiana (Bertoni) Hemsl regenerants in the culture of axillary buds.

\begin{tabular}{|c|c|c|c|c|c|c|}
\hline Auxin & $\begin{array}{l}\text { Concentration, } \\
\mathrm{mg} \mathrm{l}^{-1}\end{array}$ & $\begin{array}{l}\text { Number of } \\
\text { roots, } \\
\text { pcs./shoot }\end{array}$ & $\begin{array}{l}\text { Total root } \\
\text { length, cm }\end{array}$ & $\begin{array}{l}\text { Shoot length, } \\
\text { cm }\end{array}$ & Callus & $\begin{array}{l}\text { The yield of } \\
\text { adapted } \\
\text { plants, } \%\end{array}$ \\
\hline Control & 0.0 & $4.2 \pm 0.6^{a}$ & $4.7 \pm 0.9^{a}$ & $3.1 \pm 0.5^{a}$ & - & $78.6 \pm 3.5^{a}$ \\
\hline IBA & 0.05 & $5.4 \pm 0.5^{a}$ & $5.7 \pm 0.8^{b}$ & $2.9 \pm 0.3^{a}$ & - & $77.4 \pm 4.1^{a}$ \\
\hline & 0.1 & $6.8 \pm 0.4^{b}$ & $6.5 \pm 0.4^{b}$ & $3.2 \pm 0.4^{\mathrm{a}}$ & - & $85.2 \pm 4.3^{b}$ \\
\hline
\end{tabular}




\begin{tabular}{cllllll}
\hline & & & & & \\
\hline & 0.2 & $7.4 \pm 0.3^{\mathrm{b}}$ & $7.7 \pm 0.6^{\mathrm{c}}$ & $2.9 \pm 0.4^{\mathrm{a}}$ & - & $83.2 \pm 3.9^{\mathrm{b}}$ \\
& 0.4 & $8.7 \pm 0.6^{\mathrm{c}}$ & $8.1 \pm 0.8^{\mathrm{c}}$ & $3.0 \pm 0.6^{\mathrm{a}}$ & - & $84.7 \pm 5.0^{\mathrm{b}}$ \\
& 0.6 & $9.9 \pm 1.1^{\mathrm{d}}$ & $10.2 \pm 1.0^{\mathrm{d}}$ & $2.8 \pm 0.2^{\mathrm{a}}$ & - & $100.0^{\mathrm{a}} \pm .0^{\mathrm{c}}$ \\
& 0.8 & $11.6 \pm 1.2^{\mathrm{e}}$ & $9.0 \pm 1.1^{\mathrm{e}}$ & $2.9 \pm 0.3^{\mathrm{a}}$ & - & $100.0 \pm 0.0^{\mathrm{c}}$ \\
& 1.0 & $10.9 \pm 0.9^{\mathrm{d}}$ & $10.6 \pm 1.2^{\mathrm{d}}$ & $3.7 \pm 0.4^{\mathrm{b}}$ & - & $100.0 \pm 0.0^{\mathrm{c}}$ \\
& 1.0 & $10.6 \pm 1.2^{\mathrm{d}}$ & $3.6 \pm 0.3^{\mathrm{f}}$ & $1.9 \pm 0.1^{\mathrm{c}}$ & + & $50.2 \pm 4.1^{\mathrm{d}}$ \\
& 2.0 & $10.1 \pm 0.9^{\mathrm{d}}$ & $3.4 \pm 0.2^{\mathrm{f}}$ & $1.9 \pm 0.2^{\mathrm{c}}$ & + & $47.1 \pm 3.5^{\mathrm{d}}$ \\
& 3.0 & $3.9 \pm 0.4^{\mathrm{a}}$ & $4.5 \pm 0.4^{\mathrm{a}}$ & $2.9 \pm 0.3^{\mathrm{a}}$ & - & $76.7 \pm 4.7^{\mathrm{a}}$ \\
& 0.05 & $7.3 \pm 0.8^{\mathrm{b}}$ & $6.5 \pm 0.6^{\mathrm{b}}$ & $3.8 \pm 0.4^{\mathrm{d}}$ & - & $77.9 \pm 3.9^{\mathrm{a}}$ \\
& 0.1 & $10.1 \pm 1.2^{\mathrm{d}}$ & $11.0 \pm 1.3^{\mathrm{d}}$ & $3.8 \pm 0.3^{\mathrm{d}}$ & - & $100.0 \pm 0.0^{\mathrm{c}}$ \\
& 0.2 & $4.2 \pm 0.5^{\mathrm{a}}$ & $4.9 \pm 0.7^{\mathrm{a}}$ & $3.0 \pm 0.2^{\mathrm{a}}$ & - & $78.4 \pm 4.5^{\mathrm{a}}$ \\
& 0.4 & $4.2 \pm 0.5^{\mathrm{a}}$ & $5.1 \pm 0.5^{\mathrm{a}}$ & $2.8 \pm 0.4^{\mathrm{a}}$ & - & $77.9 \pm 4.6^{\mathrm{a}}$ \\
& 0.6 & $2.6 \pm 0.4^{\mathrm{f}}$ & $3.5 \pm 0.3^{\mathrm{f}}$ & $2.1 \pm 0.3^{\mathrm{c}}$ & + & $60.1 \pm 3.8^{\mathrm{e}}$ \\
& 0.8 & $2.6 \pm 0.5^{\mathrm{f}}$ & $3.5 \pm 0.3^{\mathrm{f}}$ & $1.8 \pm 0.3^{\mathrm{c}}$ & + & $57.3 \pm 2.7^{\mathrm{e}}$ \\
& 1.0 & $2.4 \pm 0.3^{\mathrm{f}}$ & $2.7 \pm 0.4^{\mathrm{f}}$ & $1.7 \pm 0.2^{\mathrm{c}}$ & + & $46.4 \pm 4.6^{\mathrm{d}}$ \\
& 2.0 & $1.2 \pm 0.1^{\mathrm{g}}$ & $1.6 \pm 0.2^{\mathrm{g}}$ & $1.7 \pm 0.1^{\mathrm{c}}$ & + & $48.6 \pm 4.2^{\mathrm{d}}$ \\
\hline
\end{tabular}

Note: Parameters have been recorded after 3 weeks of transfer in rooting media. Data are in the form of mean \pm SEM, and means followed by the same letter within the columns are not significantly different at $\mathrm{P}<0.05$.

The stimulating effect of IAA on the development of the root system in stevia shoots was observed at concentrations of $0.1-0.2$ mg $\mathrm{I}^{-1}$. When the hormone was added at a concentration of $0.4-0.6 \mathrm{mg} \mathrm{l}^{-1}$, the number and length of the roots did not differ from the control. Increasing the dose of IAA in the nutrient medium caused a decrease in the parameters of the root system. In addition, the use of higher concentrations both of IBA (2-3 $\left.\mathrm{mg} \mathrm{l}^{-1}\right)$ and IAA (0.8-3 $\left.\mathrm{mg} \mathrm{l}^{-1}\right)$ stimulated the development of callus on the basal shoots and inhibited their rooting. According to Debnath (2008) data, the best result of stevia rooting was found when 2 mg I $^{-1}$ IBA was added to the MS nutrient medium. Ahmed et al. (2007) discovered that micro cuttings taken from the in vitro proliferated shoots initiated the maximum frequency of rooting (97.66\%) in MS medium fortified with $0.1 \mathrm{mg} \mathrm{I}^{-1}$ IAA. Thus, according to our research, the adding $0.6-1.0 \mathrm{mg} \mathrm{l}^{-1}$ IBA or $0.2 \mathrm{mg} \mathrm{l}^{-1}$ IAA to the $B_{5}$ medium is effective for the in vitro rooting of the shoot fragments of $S$. rebaudiana.

When plants are propagated in tissue culture, the stage of adaptation of regenerants to ex vitro cultivation is one of the most important (Pospisilova et al., 1999; Pérez et al., 2015; Vahdati et al., 2017). This is the final stage of micropropagation and the death of most of the planting material significantly reduces its effectiveness. For the successful adaptation of regenerants, it is necessary to create optimal conditions for the further growth and development of both the aerial part of plants and their root system. The proposed methods for acclimatizing various plants to ex vitro conditions are very diverse (Pospisilova et al., 2007, 2009; Pérez et al., 2015; Huh et al., 2017; Emara, 2018; Hoang et al., 2019). To adapt the stevia regenerants, we used a hydroponic setup. Plants were fixed in cassettes and placed in a vegetative cuvette filled with a nutrient solution (30 I) containing the concentration of mineral salts according to the quarter-strength MS basal medium prescription. During the first week of adaptation, we used the tripled concentration of $\mathrm{KH}_{2} \mathrm{PO}_{4}\left(510 \mathrm{mg} \mathrm{l}^{-1}\right)$ in comparison with the content of this substance in $\mathrm{MS}$ basal medium $\left(170 \mathrm{mg} \mathrm{l}^{-1}\right)$. Over the next 2 weeks, regenerants were adapted in a solution containing mineral salts of the quarterstrength MS basal medium, with the exception of the concentration of $\mathrm{NH}_{4} \mathrm{NO}_{3}$, which was left unreduced $\left(1650\right.$ mg $\mathrm{I}^{-1}$ ). Thus, the adaptation period was 3 weeks.

The yield of adapted plants on average for all options was $75.2 \%$. Significant differences in comparison with the control were

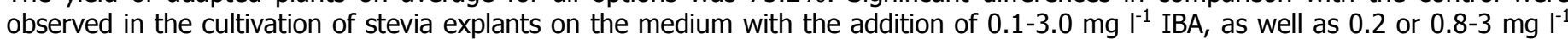
IAA. The maximum yield of surviving plants (100\%) was found to occur when both $0.6-1 \mathrm{mg} \mathrm{l}^{-1}$ IBA and $0.2 \mathrm{mg} \mathrm{l}^{-1}$ IAA were added to the culture medium. In cases where callus develops on the basal part of the stevia shoot fragments, short thick roots without root hairs are usually formed. As a result, despite the high proportion of in vitro rooted plants, the yield of regenerants adapted to ex vitro conditions is low. This can probably be explained by a violation of the vascular connection between the roots and stems. In addition, in poorly developed lateral roots, changes in the vascular system and hypertrophy of the cortical layer are also noted.

One of the possible approaches to solving the problem of adaptation is to create conditions for regenerants during in vitro cultivation, under which they do not form the so-called "cultural phenotype". This specific phenotype includes a number of physiological, anatomical and metabolic features of plants induced by culture conditions (Isah, 2015; Martins et al., 2019). These changes relate primarily to leaves. When cultivated in a nutrient medium, plants are provided with photomixotrophic nutrition. Heterotrophic micropropagation is provided by sucrose, and autotrophic one is due to the process of photosynthesis. The carbon dioxide in the vessel is quickly exhausted, therefore, inhibition of autotrophic growth occurs. A deficit of carbon dioxide causes a corresponding adaptation of the assimilation tissue of the leaves, a change in the functional activity of the photosynthetic apparatus and the state of the closing stomata cells. In addition, air humidity close to saturating, the absence of a gradient of water potential between the evaporating surface of the leaves and the atmosphere lead to inhibition of transpiration. As a result, the water-holding capacity in leaves of regenerants is reduced because of the weak activity of the stomatal apparatus, poorly developed cuticle, and reduced osmotic potential (Pospisilova et al., 1999; Xiao et al., 2011; Barupa et al., 2018; Krisantini and Wiendi, 2018). Thus, a specific complex of in vitro culture factors causes adequate adaptive responses of plants. But in vivo, after transferring regenerants to ex vitro conditions, such adaptations are impracticable, since irreversible dehydration of regenerated plants occurs. "Cultural phenotype" is also determined by the characteristics of the root system of regenerants. It is often characterized by the absence of root hairs and second-order roots. For this reason, regenerants have a small feeding area and low absorption capacity, which also negatively affects plants at the stage of their adaptation to ex vitro conditions.

Therefore, at the last stage of micropropagation, it is necessary to develop these in vitro conditions under which regenerants will be able to switch from heterotrophic nutrition to mixotrophic or autotrophic ones. This way of plant nutrition will create the prerequisites for the successful development of plants during acclimatization under new ex vitro conditions. Photoautotrophic tissue culture is in vitro propagation without or with a reduced sugar levels in the culture media. As a result, the growth or accumulation of carbohydrates by explants depends on photosynthesis and inorganic nutrient uptake (Nguyen and Kozai, 2005; Kozai, 2010). The photomixotrophic technique involves various approaches.

They are an increase in light intensity, a decrease in sugar concentration, an addition of porous materials such as vermiculite, gum and paper pulp to liquid or agar media, $\mathrm{CO}_{2}$ enrichment either by using a permeable gas filters for vessel caps or by supplying $\mathrm{CO}_{2}$ directly into the vessels which ensures gas exchange. These manipulations during the micropropagation lead to changes in cuticular 
wax deposit, increased stomatal density, ion exchange in guard cells of stomata during opening and closure, increased mesophyll layers (Mitra et al., 1998; Xiao et al., 2011; Isah, 2015; Pérez et al., 2015; Emara, 2018; Krisantini and Wiendi, 2018; Hoang et al., 2019; Martins et al., 2019). In addition, an important advantage of the technique is drastic reduction in contamination due to noninclusion of sugar in the medium and use of non-agar supporting matrix (Kaur, 2015). The photomixotrophic technique affects growth parameters of regenerants during multiplication and rooting and can help plantlets cope with the challenging ex vitro conditions during acclimatization stage.

In our study, to increase the adaptive ability of stevia regenerants during acclimatization, we replaced agar with a mixture of perlite and vermiculite in the last subculture medium. A mixture $(2 \mathrm{~g})$ in a ratio of $1: 3$ (perlite : vermiculite) was placed in a 250 ml flask into which $B_{5}$ liquid nutrient medium was added for rooting. Regenerants cultured on the substrate for 3 weeks. The use of a porous substrate provided a decrease in humidity inside the vessels. As a result, leaves with well-functioning stomata formed on growing shoots. These stevia regenerants well tolerated a change in growing conditions. They were planted in the ground and did not require shelter with plastic wrap to create a special chamber for high humidity. The moist substrate remaining on the roots after removing the plants from the flasks contained residues of the nutrient medium and thereby provided regenerants with mineral substances in the first days of their acclimatization to ex vitro conditions. The survival rate of stevia regenerants in the greenhouse was $100 \%$. In addition, the use of such a composition for rooting stevia regenerants is more economical, as it reduces the cost of the substrate.

\section{Conclusion}

We concluded that the adding $0.6-1.0 \mathrm{mg} \mathrm{l}^{-1}$ IBA or $0.2 \mathrm{mg} \mathrm{l}^{-1}$ IAA to the $\mathrm{B}_{5}$ medium is effective for the in vitro reproduction and rooting the shoot fragments of Stevia rebaudiana (Bertoni) Hemsl. A two-stage technique for adapting regenerated plants to ex vitro conditions using hydroponic setup filled with a solution of mineral salts according to the quarter-strength MS basal medium modified at each stage of adaptation by the content of $\mathrm{KH}_{2} \mathrm{PO}_{4}$ and $\mathrm{NH}_{4} \mathrm{NO}_{3}$ characterized by high efficiency and allows you to get plants with a well-developed root system and shoot. Using a triple concentration of $\mathrm{KH}_{2} \mathrm{PO}_{4}\left(510\right.$ mg $\left.\mathrm{I}^{-1}\right)$ during the first week of adaptation and a full concentration of $\mathrm{NH}_{4} \mathrm{NO}_{3}\left(1650 \mathrm{mg} \mathrm{l}{ }^{-1}\right)$ over the next 2 weeks ensures $100 \%$ acclimatization of stevia regenerants to ex vitro conditions. The replacement of agar in the nutrient medium with a perlite-vermiculite mixture in the ratio of $1: 3$ stimulated the transition of regenerants under in vitro conditions to the photomyxotrophic type of nutrition. The use of a porous substrate provided a decrease in humidity inside the culture vessels, which led to forming both leaves with well-functioning stomata and a branched root system with root hairs. The stevia regenerants propagated in vitro on a porous substrate did not require special conditions for the ex vitro acclimatization (for example, shelters with plastic bags to provide increased humidity) and can be transferred from culture flasks to a greenhouse or field. The yield of surviving plants in the greenhouse was $100 \%$.

\section{References}

Ahmed, M. B., Salahin, M., Karim, R., Razvy, M. A., Hannan, M. M., Sultana, R., Hossain, M., \& Islam, R. (2007). An efficient method for in vitro clonal propagation of a newly introduced sweetener plant (Stevia rebaudiana Bertoni) in Bangladesh. American-Eurasian Journal of Science and Research, 2, 121-125.

Barupa, M., Kataria, V., \& Shekhawat, N. S. (2018). In vitro growth profile and comparative leaf anatomy of the C3-C4 intermediate plant Mollugo nudicaulis Lam. In Vitro Cellular \& Developmental Biology - Plant. doi.org/10.1007/s11627-018-9945-7

Bhingradiya, V., Mankad, A., Patel, R., \& Mathur, Sh. (2016) In vitro shoot multiplication of Stevia rebaudiana (Bert.) through plant tissue culture Int. J. Adv. Res., 4(11), 2300-2307.

Brandle, J. E., \& Telmer, P. G. (2007). Steviol glycoside biosynthesis. Phytochemistry, 68, 1855-1863.

Chatsudthipong, V., \& Muanprasat, C. (2009). Stevioside and related compounds: Therapeutic benefits beyond sweetness. Pharmacology \& Therapeutics, 121, 41-54.

Debnath, M. (2008). Clonal propagation and antimicrobial activity of an endemic medicinal plant Stevia rebaudiana. Journal of Medicinal Plant Research, 2, 45-51.

Emara, H. A., Nower, A. A., Hamza, E. M., \& El Shaib, F. (2018). Evaluation of photomixotrophic technique and several carbohydrate sources as affecting banana micropropagation. Int. J. Curr. Microbiol. App. Sci, 7(10), 788-804.

Frederico, A. P., Ruas, P. M., Marin-Morales, M. A., Fuas, C. F., \& Nakajima, J. N. (1996). Chromosome studies in some Stevia Cav. (Compositae) species from Southern Brazil. Brazilian Journal of Genetics, 19, 605-609.

Galdina, T. E. (2015). Development of the complex technology of cultivation of Stevia rebaudiana (Bertoni) Hemsl. in the conditions of Central Black Earth Region. Science Almanac, 8(10), 1141-1143. (In Russian)

Gantait, S., Das, A., \& Mandal, N. (2014). Stevia: a comprehensive review on ethnopharmacological properties and in vitro regeneration. Sugar Tech.

Ghaheri, M., Kahrizi, D., \& Bahrami, Gh. (2017). Effect of mannitol on some morphological characteristics of in vitro Stevia rebaudiana Bertoni. Biharean biologist, 11(2), 94-97.

Ghorbani, T., Kahrizi, D., Saeidi, M., \& Arji, I. (2017). Effect of sucrose concentrations on Stevia rebaudiana Bertoni tissue culture and gene expression. Cell Mol Biol (Noisy le Grand), 63, 8, 32-36.

Hoang, N. N., Kitaya, Yo., Shibuya, T., \& Endo R. (2019). Development of an in vitro hydroponic culture system for wasabi nursery plant production - Effects of nutrient concentration and supporting material on plantlet growth. Scientia Horticulturae, 245, 237243.

Huh, Y. S., Lee, J. K., \& Nam, S. Y. (2017). Improvement of ex vitro acclimatization of mulberry plantlets by supplement of abscisic acid to the last subculture medium. J Plant Biotechnol, 44(4), 431-437. DOI: https://doi.org/10.5010/JPB.2017.44.4.431/

Isah, T. (2015). Adjustments to in vitro culture conditions and associated anomalies in plants. Acta biologica Cracoviensia. Series Botanica, 57/2, 9-28.

Islam, S. A. M. N., \& Tareq, S. A. M. (2015). In vitro cloning and stem cutting of stevia (Stevia rebaudiana Bertoni) for mass propagation in Chittagong, Bangladesh. The International Journal of Biotechnology, 4(3), 14-19.

Jain, P., Kachhwaha, S., \& Kothari, S. L. (2014). Biotechnology and metabolic engineering of Stevia rebaudiana (Bert.) Bertoni: perspective and possibilities. Int. J. LifeSc. Bt \& Pharm. Res., 3, 3, 15-37.

Kaur, R. P. (2015). Photoautotrophic micropropagation an emerging new vista in micropropagation - A review. Agricultural Reviews, 36(3), 198-207. 
Kononova, Ye. A., Krivenko, A. A., \& Chukhlebova, N. S. (2012). Induction of flowering and seed production of di- and tetraploid stevia varieties in Leached Black Soil of the Central Ciscaucasia. Nauchnyi zhurnal KubGAU (Scientific Journal of the Kuban State Agrarian University), 76(02). http://ej.kubagro.ru/2012/02/pdf/42.pdf/ (In Russian)

Kovylyaeva, G. I., Bakaleinik, G. A., Strobykina, I. Y., Gubskaya, V. I., Sharipova, R. R., Al'Fonsov, V. A., Kataev, V. E., \& Tolstikov, A. G. (2007). Glycosides from Stevia rebaudiana. Chemistry of Natural Compounds, 43, 1, 81-85.

Kozai, T. (2010). Photoautotrophic micropropagation - environmental control for promoting photosynthesis. Prop. Ornam. Plants, $10,188-204$.

Krisantini, \& Wiendi N. M. (2018). Photoautotrophic system: A review and potential applications in plant micro propagation. Journal of Tropical Crop Science, 5, 2, 73-77.

Kumar, R. (2013). Seed germination of Stevia rebaudiana influenced by various potting media. Octa Journal Biosciences, 1 , 143146.

Kustova, O. K. (2013). Biomorphologic characteristics of Stevia rebaudiana (BertonI) Hemsl. in generative age state. Industrial botany, 13, 252-258. (In Russian)

Madan, S., Ahmad, S., Singh, G. N., Kohli, K., Kumar, Y., Singh, R., \& Garg, M. (2010). Stevia rebaudiana (Bert.) Bertoni - A review. Indian Journal of Natural Products and Resources, 1, 267-286.

Martins, J. P. R., Rodrigues, L. C. D. A., Conde, L. T., Gontijo, A. B. P. L., \& Falqueto, A. R. (2019). Anatomical and physiological changes of in vitro-propagated Vriesea imperialis (Bromeliaceae) in the function of sucrose and ventilated containers. Plant Biosystems-An International Journal Dealing with all Aspects of Plant Biology, 1-13.

Mitra, A., Bhattacharya, P. S., Dey, S., Sawarkar, S. K., \& Bhattacharyya, B. C. (1998). Photoautotrophic in vitro culture of Chrysanthemum under $\mathrm{CO}_{2}$ enrichment. Biotechnology Techniques, 12, 335-337.

Nguyen, T. Q., \& Kozai T. (2005). Photoautotrophic (sugar-free medium) micropropagation as a new propagation and transplant production systems. Springer, Dordrecht, the Netherlands.

Pande, S. S., \& Gupta, P. (2013). Plant tissue culture of Stevia rebaudiana (Bertoni): A review. Journal of Pharmacognosy and Phytotherapy, 5(1), 26-33.

Pérez, L. P., Montesinos, Ye. P., Olmedo, Ju. G., Sánchez, R. R., Montenegro, O. N., Rodriguez, R. B., Ribalta, O. H., Escriba, R. C. R., Daniels, D., \& Gómez-Kosky R. (2015). Effects of different culture conditions (photoautotrophic, photomixotrophic) and the auxin indole-butyric acid on the in vitro acclimatization of papaya (Carica papaya L. var. Red Maradol) plants using zeolite as support. Afr. J. Biotechnol., 14(35), 2622-2635. DOI: 10.5897/AJB2015.14814/

Pospisilova, J., Synkova, H., Haisel, D., \& Semoradova, S. (2007). Acclimation of plantlets to ex vitro conditions: Effects of air humidity, irradiance, $\mathrm{CO}_{2}$ concentration and abscisic acid (a Riview). Acta Horticulturae, 748. DOI: 10.17660/ActaHortic.2007.748.2

Pospisilova, J., Ticha, I., Kadlecek, P., Haisel, D., \& Plzakova, S. (1999). Acclimatization of micropropagated plants to ex vitro conditions. Biologia Plantarum, 42, 481-497.

Pospisilova. J., Synkova, H., Haisel, D., \& Batkova, P. (2009). Improvement of ex vitro transfer of tobacco plantlets by addition of abscisic acid to the last subculture. Biologia Plantarum, 53, 617-624.

Sikorskaya, S. V. (2004). Biomorphological traits of stevia (Stevia rebaudiana (Bertoni) Hemsl.) under introduction in conditions of the Central Black Soil Region of Russia. Extended Abstract Cand. Sci. (Biol.) Dissertation, Kursk. (In Russian)

Singh, M., Saharan, V., Dayma, J., Rajpurohit, D., Sen, Y., \& Sharma, A. (2017). In vitro propagation of Stevia rebaudiana (Bertoni): An overview. International Journal of Current Microbiology and Applied Sciences, 6, 7, 1010-1022.

Skaria, B. P., Joseph, R., Mathew, G., Malhew, S., \& Joy, P. P. (2004). Stevia: A sweet herb. Indian Journal of Arecanut Spices and Medicinal Plants, 6, 24-27.

Smitha, G. R., \& Umesha, K. (2011). Vegetative propagation of stevia (Stevia rebaudiana (Bertoni) Hemsl.) through stem cuttings. Journal of Tropical Agriculture, 50, 72-75.

Vahdati, K., Asayesh, Z. M., \& Aliniaeifard, S. (2017). Improvement of ex vitro desiccation through elevation of $\mathrm{CO}_{2}$ concentration in the atmosphere of culture vessels during in vitro growth. Hortscience, 52(7), 1006-1012. DOI: 10.21273/HORTSCI11922-17

Verzilina, N. D. (2005). Stevia (Stevia rebaudiana Bertoni) in the Central Black Earth Region (Agrobiological, physiological and biochemical aspects of its cultivation), Dr. Sci. (Agr.) Dissertation, Voronezh. (In Russian)

Xiao, Y., Niu, G., \& Kozai T. (2011). Development and application of photoautotrophic micropropagation plant system. Plant Cell Tissue Organ Cult, 105, 49-158.

\section{Citation:}

L.P. Khlebova, A. Orazov, A.M. Titova, A.V. Pirogov (2019). Adaptation to ex vitro conditions of Stevia rebaudiana (Bertoni) Hemsl. regenerants. Ukrainian Journal of Ecology, 9(3), 376-380.

(cc) $\mathbf{E Y}$ This work is licensed under a Creative Commons Attribution 4.0. License 